\title{
Aesthetic Hedonism and Its Critics
}

\author{
Servaas van der Berg
}

\section{(This is the penultimate draft. Please cite the published version-published in Philosophy Compass and available here: https://doi.org/10.1111/phc3.12645)}

\begin{abstract}
This essay surveys the main objections to aesthetic hedonism, the view that aesthetic value is reducible to the value of aesthetic pleasure or experience. Hedonism is the dominant view of aesthetic value, but a spate of recent criticisms has drawn its accuracy into question. I introduce some distinctions crucial to the criticisms, before using the bulk of the essay to identify and review six major lines of argument that hedonism's critics have employed against it. Whether or not these arguments suffice to refute hedonism decisively, I argue that its privileged status, as the sole contender in aesthetic value theory, is detrimental to downstream research on aesthetic phenomena. The essay concludes with an overview of current work and promising avenues of inquiry into non-hedonic alternatives.
\end{abstract}

\section{INTRODUCTION}

Aesthetic hedonism holds that aesthetic value is a special kind of hedonic value - that is, an item's aesthetic value is simply its power to please us in a certain way. ${ }^{1}$ If we construe hedonism broadly, it would be fair to say that contemporary aesthetic value theory has been thoroughly dominated by a hedonist consensus. ${ }^{2}$ This is hardly surprising. Boasting a generous share of intuitive plausibility, hedonism could arguably lay claim to being the common sense view of

\footnotetext{
${ }^{1}$ Some propose hedonism as an account of artistic rather than aesthetic value. For ease of exposition, both are treated here under the banner of aesthetic hedonism and the difference is marked only where needed. For discussion of the artistic/aesthetic value distinction, see Lopes (2011), Huddleston (2012), Stecker (2012), Hanson (2013), Dodd (2014), and Forsey (2017).

2 The consensus is defended in the very first paper this journal published (Stecker 2006). For other contemporary articulations of aesthetic hedonism see Dickie (1988), Mothersill (1989), Levinson (1992, 2002, 2016), Walton (1993), Stephen Davies (1994), Budd (1985, 1995, 2008), Iseminger (2004, 2005), Goldman (1995, 2006), Stang (2012), and Matthen (2017, 2018). Many others working in aesthetics endorse some form of the view. For a more extensive though probably still not exhaustive list of its proponents, see Lopes (2018: 9).
} 
aesthetic value. After all, who would deny that our encounters with the aesthetic are often a source of great enjoyment, and, occasionally, of transcendent delight? From here it is a short step to the hedonist doctrine that an item's aesthetic value is constituted by its relation to such pleasure or valuable experience.

Lately, however, resistance has been on the uptick. Among a growing list of dissenters, James Shelley $(2010,2011,2013,2017,2019)$ and Dominic Lopes $(2015,2018)$ have proven especially persistent and methodical in their opposition to aesthetic hedonism. ${ }^{3}$ But while the challenges mount, replies from within the hedonist camp have so far been scarce and, at best, perfunctory. A real debate about the view's strengths and shortcomings, and about what the alternatives look like, is only now getting properly under way. This essay aims to aid in the debate by cataloguing the main extant arguments against aesthetic hedonism and thereby mapping the territory for its defenders and detractors alike. Section 2 homes in on some key distinctions, setting up the review of counterarguments to hedonism in Section 3. Section 4 asks: if not hedonism, then where might work on aesthetic value go next?

\section{FAULT LINES IN THE DEBATE}

Three preliminary distinctions can help shed light on features of aesthetic hedonism that have been targeted by the recent criticisms. The way in which particular hedonist theories situate themselves with respect to these distinctions will affect which counterarguments they are most vulnerable to.

\subsection{Demarcation versus normativity}

First, it is fast becoming standard among hedonism's critics to flag a distinction between two questions that a complete theory of aesthetic value should answer (Shelley 2019: 1, Lopes 2018: 41-3, 2019, King 2019, Gorodeisky 2019, Matherne \& Riggle ms., Matherne ms., Peacocke

\footnotetext{
3 Other critics of aesthetic hedonism include Sharpe (2000), David Davies (2004), Kieran (2005, 2008), Wolf (2010), Watkins and Shelley (2012), Riggle (2013, 2015), Gorodeisky (2019), Matherne \& Riggle (ms.), and Peacocke (ms.).
} 
ms.). The 'demarcation question' asks what makes aesthetic values aesthetic - what distinguishes them from values in other domains? The 'normative question' asks what makes aesthetic values values? One might understand the normative question in terms of reasons: what makes it the case that aesthetic values give us reasons for anything? Part of aesthetic hedonism's appeal lies in its promise to bridge intuitive answers to both questions. It answers the normative question by reducing aesthetic value to hedonic value: aesthetic values generate reasons because we have reason to pursue pleasure, and the experiences said to ground aesthetic values are pleasures, or, at the very least, they are finally valuable like pleasures, such that we have non-derivative reason to pursue them (see Section 2.2). With respect to the demarcation question, aesthetic hedonism does not entail an answer, but it nonetheless recommends an approach by pointing to a theory of aesthetic experience. Whatever distinguishes aesthetic pleasures or experiences from nonaesthetic ones, the thought goes, will determine which of the values grounded in pleasant or finally valuable experience (that is, which hedonic values) are distinctively aesthetic.

Unfortunately, agreement on the nature of aesthetic experience has proven elusive, with the result that this has become a main focal point for work on aesthetic value (see for example Iseminger 2005, Stecker 2006, Goldman 2006, Carroll 2002, 2012, Levinson 2016). The move to flag the demarcation/normativity distinction serves as a corrective for this tendency, by reminding us that hedonism's success turns on more than just a consensus account of aesthetic experience. Just as important is its answer to the normative question. To borrow Roger Crisp's (2006: 622-23) terminology: aesthetic hedonism should be evaluated not just as an enumerative theory, that pinpoints which sorts of things have aesthetic value-namely the things that offer valuable aesthetic experience. It should be evaluated also as an explanatory theory, that singles out the fundamental good-making or reason-giving features of aesthetic goods - namely the pleasantness (or some other value-grounding feature) of the experiences they offer. As we shall see, hedonism's critics have found various reasons to take issue with this answer to the normative question (see especially Sections 3.1, 3.2, and 3.4).

\subsection{Narrow versus preference hedonism}


A second distinction key to evaluating aesthetic hedonism concerns the conception of aesthetic pleasure or experience to which hedonists appeal. To get a handle on the distinction, first consider the case of theories of pleasure simpliciter. Philosophical accounts of pleasure typically fall into either of two camps (see Aydede 2014, Crisp 2006: 623-30, Sumner 1996: 87-91). On the one hand, 'felt-quality' or 'internalist' accounts take pleasures to be typified by some feature of their phenomenology: either a distinctive feeling that all pleasant experiences include, or an hedonic 'tone' they all share. In value theory beyond aesthetics, hedonists who rely on a feltquality notion of pleasure are known as narrow hedonists (see Parfit 1984: 492). On the other hand, motivated by the vast diversity of the experiences we find pleasant (the so-called heterogeneity problem for theories of pleasure), 'attitudinal' or 'externalist' accounts deny that there is a single phenomenological feature common to all pleasures. Instead, they analyse pleasure in terms of some conative or evaluative pro-attitude that a subject holds towards one of their own ongoing experiences. Thus, on an attitudinal account, pleasures are simply experiences occurrently preferred, desired, liked, or valued in the right way (the details of the pertinent proattitude vary across different attitudinal accounts). In contrast to narrow hedonism, hedonist theories that take an attitudinal view of pleasure are considered instances of preference hedonism (ibid.).

The distinction matters in the current context because it also applies to accounts of aesthetic pleasure (or aesthetic value-grounding experience, if you prefer). Contemporary aesthetic hedonism is particularly well matched with an attitudinal conception of aesthetic pleasure. Why is this the case? The heterogeneity problem remains as much a challenge for theories of aesthetic pleasure as for theories of pleasure simpliciter, but there is a second, aesthetic reason for going attitudinal, namely the problem of painful art. Some paradigmatic aesthetic goods - some artworks in particular-owe their aesthetic value to features that make them unsettling, jarring, emotionally taxing, or even painful to experience. There are various ways of coming to grips with this datum (see Strohl 2019 for an overview of research on the phenomenon), but one common strategy involves broadening the class of experiences that can ground aesthetic value to include some experiences that lack any positive hedonic tone, or even ones with decidedly negative felt quality. This move to evade the problem of painful art is among the main reasons why some contemporary aesthetic hedonists style their theories as value empiricism or 
experientialism instead of hedonism. For value empiricists, what ends up mattering to the valuegrounding role of aesthetic experiences is not any pleasant-making feature of their phenomenology, but rather that we find them 'worthwhile' (Levinson 1992: 296), or that we 'value them for their own sake' (Stecker 2006, Iseminger 2004, 2005, Budd 2008: 45-47). In other words, value empiricists conceive of aesthetic experience or pleasure in terms of an evaluative attitude, as experience preferred or finally valued rather than strictly pleasant in terms of feeling tone. They are attitudinal theorists about aesthetic experience and, by extension, aesthetic preference hedonists. This is significant because preference hedonists are vulnerable to what we might call the normativity objection (Section 3.1), and maybe some others, that narrow hedonists may safely ignore.

\subsection{Basic versus standardized hedonism}

The third distinction to play a crucial role in the objections to hedonism is the distinction between basic and standardized hedonist theories. Aesthetic hedonism faces a version of the problem of taste: propensities for pleasure vary - what gives one appreciator great aesthetic pleasure leaves another cold and makes yet another queasy. So, when two people disagree about something's aesthetic value, how should the hedonist resolve the dispute? The problem runs especially deep for response-dependent theories of aesthetic value like hedonism, because for them it is not just an epistemic matter of deciding whose experience accurately reflects the aesthetic state of the world. Aesthetic hedonists reduce aesthetic value to the value of experience, so the question for them is: whose experience fixes or constitutes the aesthetic state of the world?

Hedonists have a range of options to respond to the problem of taste. The limit case, on the most relativist side of a spectrum of possible views, settles for basic hedonism. In effect, this position indexes all aesthetic values to an individual at a time, thereby denying the intersubjective reality and temporal stability of aesthetic value: every appreciator sets their own standard; there is no beauty except in the beholder's eye; the customer is always right. This is less a solution than a rejection of the problem of taste, and not many in aesthetics have found it an attractive position, though some (such as Melchionne 2010, Kölbel 2016) have dabbled with views in the vicinity. A much more popular option lies near the other, universalist end of the spectrum. It holds that there 
is an hedonically ideal set of propensities for aesthetic pleasure to which all should aspire, and this sets the standard for resolving disputes about taste. The ideal has come to be expressed in terms of Humean 'true judges', in large part owing to Mary Mothersill (1989) and Jerrold Levinson's (2002) influential hedonist interpretation of Hume's (1757) solution to the problem of taste. On their reading of Hume, the true judges are idealized creatures whose sensibilities are perfectly calibrated for the maximization of aesthetic pleasure, such that their hypothetical joint verdict on matters of aesthetic value fixes the aesthetic facts.

The timeless and universal standard of Humean true judges has been extremely influential and, as a result, the middle of the spectrum of possible hedonisms is almost as sparsely populated as the relativist end. An interesting recent exception is due to Mohan Matthen (2017, 2018), who tries to balance the variance in our hedonic responses with a sophisticated account of how those responses are malleable and subject to cultural learning. Matthen defines aesthetic pleasure functionally, as a mental state that plays the role of facilitating the continuation of effortful perceptual or cognitive engagement with items of aesthetic interest. Given this definition, our propensities for feeling aesthetic pleasure will be partly determined by our perceptual and cognitive competencies. As these competencies are acquired and developed in response to constraints imposed by a cultural and historical context, Matthen's account indexes aesthetic values not to a universal standard like the true judges, but rather to a standard set by the culture in whose artistic practices they feature.

Whether or not to standardize and, if so, how, are questions pivotal to aesthetic hedonism's success. The game for hedonism's critics is to show that basic and standardized hedonism are two equally unacceptable horns of a dilemma. This explains why the true judges model, serving as proxy for the standardized horn of the dilemma, has become a regular target for counterarguments against hedonism (see Sections 3.5 and 3.6).

\section{OBJECTIONS TO AESTHETIC HEDONISM}

With the demarcation/normativity distinction drawn, a working concept of preference hedonism in place, and a generic picture of the Humean true judges in the background, the main arguments 
against aesthetic hedonism can more readily be articulated. This section identifies and reviews six such major arguments, or, more precisely, six argumentative strategies that have emerged from the literature (Sections 3.1-3.6). It concludes with some brief thoughts on how these arguments should be evaluated (Section 3.7).

\subsection{The normativity objection against preference hedonism}

The first counterargument targets aesthetic preference hedonists (read: value empiricists) in particular, by asking whether an attitudinal account of aesthetic pleasure can do the explanatory work for which they enlist it. The argument is most clearly articulated by Shelley (2019: 6-9), who attributes the core insight to Frank Sibley (2001). ${ }^{4}$ Recall first that answering the normative question requires giving not just an enumerative but also an explanatory theory of aesthetic value - a theory that singles out the fundamental good-making or reason-giving features of aesthetic goods (see Section 2.1). Here narrow aesthetic hedonists have no problem: they can point to the pleasantness of aesthetic experiences as their good-making feature. But preference hedonists do not have an equally satisfying answer. Recall that, in order to evade the problem of painful art, they opt for an attitudinal account on which some unsettling, jarring, and even painful experiences might ground their objects' aesthetic values, provided that these experiences are preferred or finally valued (see Section 2.2). The problem is that it is unclear which feature of this broader, attitudinally defined class of experiences can serve as a good-making or reasongiving feature. Shelley (2019: 9) illustrates the worry concisely:

I don't mean to be saying that Guernica's capacity for affording shocking, unsettling, dizzying, and despairing experiences cannot figure in an explanation of its value [...]. I mean to be saying that Guernica's capacity to afford such experiences cannot bring to completion an explanation of value in the way that the capacity to afford pleasure can.

\footnotetext{
${ }^{4}$ A generic form of the argument applies equally to preference hedonists in other normative domains. In the context of prudential hedonism, for example, Crisp (2007: 128-134) levels a version of the objection against Sidgwick's (1907: 126) appeal to an attitudinal account of pleasure.
} 
For aesthetic preference hedonists, some aesthetic experiences are 'pleasant' only in the sense of being preferred or finally valued, and not in the sense of having any transparently valuable phenomenological feature like a positive feeling tone. Do such experiences confer value on their objects simply in virtue of being preferred or valued? If so, then the question becomes why are they preferred or valued? Preference hedonists cannot answer that they are valued for their pleasantness, because they deny that aesthetic experiences have any phenomenological feature that could do the work of pleasantness. And with any other answer they give, they risk explaining aesthetic values with reference to some non-hedonic good-making feature and thereby giving up the ambition of an explanatory hedonism. The preference hedonist might double down and simply insist that the good-making feature of such experiences is the very fact that they are preferred or valued by the true judges. But this answer is only acceptable if one is antecedently committed to the rationality of the true judges' experiential preferences and valuings - a commitment that faces some serious challenges of its own (see Sections 3.5 and 3.6). If the objection sticks, then aesthetic preference hedonism (value empiricism) fails to offer a principled answer to the normative question and can thus be at best an enumerative theory of aesthetic value.

\subsection{Motivational arguments: the disinterest and pleasure paradox objections}

Among the main attractions of a hedonist theory of value in any normative domain is that it comes with a built-in mechanism for explaining normative motivation. If the reasons we have in a given domain are hedonic, then it is easy to see how we might come to be motivated to act on them, because pleasure is intrinsically motivating. I buy a pass to the Vancouver International Film Festival; assume that, in buying it, I act on my aesthetic reasons. The hedonist analysis of what aesthetically rationalizes my buying the pass - say, that many of the films on this year's programme offer some great aesthetic delights - can generally double as an explanation of what motivates my buying it. The second strategy for arguing against aesthetic hedonism targets its reliance on this kind of hedonic explanation of aesthetic motivation. The strategy has been implemented in two ways in the literature. 
First, some have argued that an hedonic account of aesthetic motivation is at odds with the disinterested nature of aesthetic pleasure or experience. An historically influential answer to the demarcation question, traceable to Kant's influence, identifies aesthetic values as those that elicit disinterested pleasure. Unlike the pleasures we take in things we like, want, or desire-what Kant calls 'the agreeable' - aesthetic pleasure is thought to be an elevated mental state divorced from its subject's preferences, desires, and projects. In short, on a strong construal of what disinterest entails, aesthetic pleasure is motivationally inert. Suppose we grant this way of demarcating the aesthetic. Then aesthetic pleasure cannot explain how we are motivated to pursue aesthetic goods in the way that pleasure can explain our motivation for acting on hedonic reasons more generally. Hence, aesthetic hedonism cannot rely on an hedonic account of aesthetic motivation, and this fatally undermines the view's appeal. Call this the disinterest objection. Compressed versions of this objection are articulated by Edward Bullough (1907: 108-9) and R. A. Sharpe (2000: 331), (although Sharpe does not use the term 'disinterest', instead describing the elevated mental state at issue as 'absorption' occasioned by 'serious interest'). As it stands, however, the disinterest objection is too strong. Few in aesthetics now accept the restrictive kind of disinterest requirement on which the objection is premised. Disinterest-based conceptions of aesthetic response have been facing increasing pushback in aesthetics. The reasons for this pushback vary, but they reflect a general concern with how a disinterest requirement separates the aesthetic too sharply from other aspects of our lives, such as our everyday practical concerns (Wolterstorff 2015) and our desires and deeply personal commitments (Nehamas 2007; Riggle 2016). And even for those who retain some form of disinterest requirement, it has become common practice to conceive it in weaker terms than the objection requires (see for example Levinson 1992: 298-99, Carlson \& Parsons 2008: 24-30, 105-6).

More compelling is a second, weaker argument also centred on pleasure's role in aesthetic motivation. Rather than deny that aesthetic experience is the right kind of state to motivate rational aesthetic agency (as in the disinterest objection), this second objection hones in on cases of aesthetic agency that defy explanation by hedonic motives. The argument, which is an application of the paradox of hedonism, is developed in detail by Lopes (2018: 83-6), who notes that some (perhaps many!) aesthetic pleasures are 'essential byproducts' of activities motivated 
by non-hedonic considerations (see also Elster 1983: 77, Nguyen 2019). I join the local Sunday evening drum circle on Vancouver's Spanish Banks; assume that I play as I have aesthetic reason to - my acute focus on coordinating with the group's beat is responsive to aesthetic values in the performance. Say that my focus pays off: I get into a nice groove and the result is a hit of pleasure. Caught off guard, I turn my attention to the pleasure, to savour it, but doing so breaks my focus and I lose my rhythm and the pleasure along with it. The pleasure is an essential byproduct of my well-executed drumming activity - activity that only yields pleasure when it is not executed in direct pursuit of pleasure. Note that the premise is not that all aesthetic pleasures are like this, only that some are. The problem for aesthetic hedonism is that the aesthetic reasons such pleasures generate - reasons to act in a manner that produces them and, thus, in a manner unconcerned with attaining them - paradoxically precludes these pleasures from playing a motivational role in agents acting on such reasons. Differently put, in such cases, hedonism implies that it is impossible for an agent to be motivated by the aesthetic reasons they are acting on. As Lopes (2018: 86) admits, this is a bullet that aesthetic hedonists could in principle decide to bite, but not without giving up a major source of their theory's appeal: 'Why be so sure that aesthetic values stand in constitutive relation to pleasures as long as we no longer think of aesthetic agents as just those agents who are moved to seek pleasure?'

\subsection{The instrumentality and fungibility objections}

Tradition has it that aesthetic value is non-instrumental and final - that its bearers are good for their own sake. Yet, on its face, aesthetic hedonism seems to imply that aesthetic value is purely instrumental: if an item's aesthetic value reduces to the final value of some pleasure or experience it affords, then surely it bears that value as a means to the experience. So, either aesthetic hedonists must find a way to deny that their view has this implication, and the prospects for doing so look limited, or they must concede that tradition is misguided and aesthetic value is purely instrumental and, thus, not final. Call this the instrumentality objection to aesthetic hedonism.

Why would it be bad to concede that aesthetic value is instrumental? At least two hedonists think that it need not be. Robert Stecker (1997: 254-6) positively embraces the implication that 
hedonism makes aesthetic value instrumental. Nick Stang (2012) is more circumspect. He first argues that aesthetic value is not final, ${ }^{5}$ but that this need not make it instrumental unless the final/instrumental value distinction is exhaustive. But even if the distinction does turn out to be exhaustive, and thus aesthetic hedonism does make aesthetic value instrumental, this need not be a drawback of the view, according to Stang, unless it has the further upshot that aesthetic goods are fungible. Stang's inventory of the logical options thus shows that what ultimately matters is not whether aesthetic value is instrumental or final or neither, but whether aesthetic goods can simply be traded for more convenient instrumental means to similar or better experiences. Call this refinement of the instrumentality worry the fungibility objection. To state the fanciful philosopher's version: aesthetic hedonism implies that, if we could take a designer drug or put on a VR headset providing exactly the same experience as that of engaging with some aesthetically great artwork, we would have identical aesthetic reasons to opt for the drug or headset as we would to travel to visit the museum. (It is worth noting that the fungibility objection is a close cousin of Robert Nozick's (1974: 43) famous experience machine argument that many have taken to be fatal for hedonist theories of well-being. Taking the drug or putting on the VR headset is the aesthetic analogue of plugging into the experience machine.) For a less fanciful recent statement of the fungibility objection, see King (ms.).

But aesthetic hedonists mostly agree on a response to the fungibility objection. They claim that aesthetic goods are not fungible, because the valuable experiences they offer cannot, as a matter of principle, be separated from their objects. By their very definition, these experiences are what they are, and have the value that they have, in virtue of being experiences of the items whose value they explain. In Stang's (2012: 274) words:

The experientialist can consistently maintain that artworks are essential constituents of the finally valuable experiences they afford. Experientialism is not committed to the fungibility of works of art.

5 Stang's arguments are formulated with respect to artistic value but apply just as well to aesthetic value. Nothing important here rests on the difference (see footnote 1). 
Others who implement versions of this response include Malcolm Budd (1985: 123-4), Levinson (1992: 304), Stephen Davies (1994: 315-16), and Alan Goldman (2006: 339). Whether we should accept it, however, is a matter on which hedonism's critics come apart. Lopes (2018: 57) concedes the response and opts to look for hedonism's shortcomings elsewhere, but Shelley (2010) is less convinced. As he sees it, once the hedonist makes the item whose aesthetic value they want to explain an essential constituent of the experience, they cannot avoid explaining the experience's value in terms of value that the item has independently of the experience. Thus, he argues, aesthetic hedonists manage to evade the fungibility objection only at the cost of rendering their answer to the normative question viciously circular: they explain the value of an item by appeal to the value of an experience of it, and the value of the experience by appeal to the value of the item (Shelley 2010: 711, see also Shelley 2017: Section 2.4, and Watkins \& Shelley 2012: $343-5)$.

\subsection{The under-articulation objection}

In the course of a programmatic attack on welfarist theories of value - that is, theories that aim to reduce all values to considerations of well-being - Susan Wolf (2015: 76) makes the following observation about comparative value judgements (her example is a comparison of the novels Middlemarch and The Da Vinci Code):

The complexity of the novel's structure, the quality of the prose, the depth and subtlety of the character development, the insights into civil society, all go into explaining why Middlemarch is a better novel. But why is it better for us to read a novel that is better in these ways?

The problem Wolf is onto is that a theory of value must, at least in principle, be able to account for every value difference in the domain it aims to explain. If, for example, welfarism is true of a normative domain, then every difference pertinent to something's value in that domain should show up as a corresponding difference in some hypothetical agent's well-being. Part of the reason this is a challenging requirement in the aesthetic domain is that our aesthetic thought and discourse recognizes fine grained value differences across many dimensions of variation in items 
of aesthetic interest-differences, for example, in a novel's complexity, depth, subtlety, insightfulness, etc. As Wolf points out, there do not always seem to be obvious corresponding differences in how the items in question are better or worse for anyone-in the sense of contributing to or detracting from their well-being. This leaves the welfarist unable to account for how such differences in the items under consideration could matter to their value.

Although Wolf's complaint targets welfarism about value in general, it can be recast in doubly restricted form as a challenge to hedonism about aesthetic value. Her choice of example makes clear that the worry applies to theories of aesthetic value as much as theories of other normative domains. And limiting the objection's target to hedonism (as opposed to welfarism more generally) only increases its bite, because unlike welfarism, hedonic explanations of value can appeal only to differences in what is good for someone to experience, and not what is good for them in some other way. Thus, restricted to aesthetic hedonism, the objection may be parsed as follows: not every difference in an item's aesthetic value recognized by our discourse and thought seems to show up as an independent difference in value-conferring properties of someone's experience of the item. The aesthetic domain is densely articulated with value differences; by contrast, our experiences do not exemplify sufficiently fine grained, aptly ordered, and independent differences in value to map cleanly onto the aesthetic value differences they are meant to explain. Call this the under-articulation objection against aesthetic hedonism.

Statements of the objection have tended to take a similar dialectical form to Wolf's challenge to the welfarist: pointing to an aesthetic value difference and then demanding that the hedonist provide an explanation of that difference in terms of their theory. This makes the force of the argument apparent, as any explanation that the hedonist might attempt is likely to flirt with circularity. Here, for example, is David Davies (2001: 258-9) on a difference in his experience of a Turner painting upon coming to understand it:

It is certainly conceivable that my 'informed' experience differs in certain respects from my relatively 'uninformed' experience. But surely this is because I am now aware of $a$ value that the picture has. The difference in experience is to be explained in terms of a recognition of a value ascribable to the work. This value does not itself 
consist in the difference of experience [...], but itself accounts for the difference in experience.

And here is Shelley (2019: 8), making a version of the same point by noting that

the property that purports to explain the intrinsic value of the experience to which the empiricist appeals must be a property of the experience itself and not merely a property of the object that affords the experience [...]. Gracefulness is a value we experience a graceful dance as having, not a value of the experience that a graceful dance affords.

The challenge for the hedonist is to point out specific valuable properties in experience without appealing to the object-attributed properties whose value they are meant to explain. The hedonist's inability to do so seems to show that the only candidate experiential properties in the vicinity depend for their value on antecedent values of the objects experienced. Such properties cannot do the necessary explanatory work; experience lacks the articulation in value-conferring properties necessary for serving as explanans in a theory of aesthetic value.

\subsection{The overvaluation argument}

Any feasible theory of aesthetic value should be able to account for mistaken attributions of aesthetic value. To that end, aesthetic hedonists standardly append a cognitive rider to their view: the experiences or pleasures that ground an item's value should be rooted in a correct understanding of the item. This allows hedonists to chalk up mistaken value attributions to an appreciator's defective grasp of an item's nature or properties. A fifth line of argument against aesthetic hedonism asks how this cognitive rider can be squared with hedonism's answer to the normative question. If pleasure is what ultimately matters, then why should the cognitive rider (or, for that matter, any non-hedonic constraint on which pleasures are the right ones) be allowed to get in the way of our taking the most or greatest pleasure possible from mediocre or even inferior aesthetic goods? Lopes (2018: 77-78) points out that this is the aesthetic analogue of a more general puzzle for hedonic theories of value: pure hedonism implies that we should alter or 
even delude ourselves so as to get maximum pleasure from almost everything. Goldman (2006: $336,339)$ preemptively considers and rejects a summary version of this objection, but its most developed statement is again due to Shelley.

Shelley (2011: 215) first distinguishes two types of mistaken value attribution-overvaluations and undervaluations. Both are commonplace; fallible as we are, we routinely take great pleasure in some mediocre aesthetic goods and fail to take pleasure in goods of great aesthetic worth. But how, asks Shelley (2011: 216-17), is hedonism to capture the aesthetic harm in overvaluation? If aesthetic reasons are ultimately reasons to pursue pleasure or valuable experience, then hedonism has all the means necessary to explain the harm in our undervaluation of the excellent aesthetic goods that the Humean true judges prefer: when we undervalue, we fail to take pleasure in items

we have aesthetic reason to enjoy. But by the same token, the true judges, by failing to overvalue the mediocre goods that we fallible aesthetic agents rate highly, fail to take pleasure in items that they have aesthetic reason to enjoy. After all, the hedonist answer to the normative question recommends taking all the aesthetic pleasure one can get. The problem is that this rationalizes the error of overvaluation and thereby contravenes the cognitive rider that hedonists rightly endorse. As Shelley (2011: 217) puts it, the hedonist 'has one mechanism for explaining value and another for explaining mistaken value-attributions. If one is functioning, the other is not.'

\subsection{Against true judges}

The sixth line of attack on aesthetic hedonism consists in undermining the model of idealized appreciators on which the most sophisticated current forms of hedonism depend (see Section 2.3). To be sure, there are possible hedonisms that forego any appeal to ideal critics or Humean true judges, but none is as fully developed or widely influential as Hume-inspired, ideal-criticcentred hedonism. Subverting the ideal appreciator model would thus go a long way towards levelling the playing field between hedonism and its competitors.

Hedonism's critics have raised three complaints against the ideal appreciator model. The first is epistemic. Matthew Kieran (2008: 280-83) argues that, given the delicate nature of the sensibilities that mark the true judges, there is no way for non-ideal appreciators-even ones 
who approximate the true judges' sensibilities quite closely - to know which items they would recommend for appreciation. If Kieran is right, this implies that the true judges model is poorly suited to the task of providing ordinary appreciators guidance in the business of finding the best aesthetic goods. But this is only bad news for hedonism if providing such guidance is the point of the true judges model. Arguably, it is not. As the hedonist construes them, the true judges are an idealization for metaphysical rather than epistemic purposes. Nothing in principle prevents aesthetic hedonists from appealing to an idealization like the true judges to fix the aesthetic state of the world, while leaving the epistemic and practical challenge of navigating that world to real, fallible, flesh-and-blood critics and appreciators.

A second complaint is stickier. It trades on the fact that the true judges, besides being an idealization, also represent an ideal: the ideal of possessing sensibilities that afford blanket access to the whole world of aesthetic value. In an exchange with Levinson (2010, 2013), who anticipates a version of the complaint, Nick Riggle $(2013,2015)$ takes issue with this picture of the aesthetic ideal. He argues that the project of cultivating the true judges' generalist sensibilities in ourselves - which the hedonist ideal recommends - is at odds with the maintenance and cultivation of our meaningful personal attachments to particular aesthetic goods. For Riggle, this amounts to a reductio of the true judges model, given the obvious importance of personal aesthetic attachments to our aesthetic lives. (For alternative articulations of the objection, see Kieran 2008: 286-93, and Lopes 2018: 81-83. See also Cross 2017, Kubala 2018).

Finally, Lopes $(2015,2018)$ develops a third complaint against the true judges model by arguing that standardized hedonism lacks resources to explain what it should. Central to its explanatory failures is, once again, the model's universalist or generalist scope. This time, however, its universalism is faulted not for posing a threat to our personal aesthetic commitments, but rather for its mismatch with the specificities of real world aesthetic action. Real world aesthetic agency (agency sensitive to aesthetic value) is deeply socially embedded, is specialized by aesthetic domain and activity, and draws on traits that are stable enough to be reliable across differences in context, but also flexible enough to adapt to novel situations (Lopes 2018: 25-31). By contrast, the expert agency modelled by the true judges floats free of social dependencies, is domain- 
general and inflexible, and is insufficiently grounded in specialized cognitive and practical skills (ibid.: 71-76). Thus, the true judges model is ill-suited to capturing the aesthetic doings of real world agents and, by extension, the values that shape those doings.

\subsection{Assessing the objections}

Stepping back from the minutiae for a moment brings the overall threat the objections pose into clearer view. Each of the six lines of argument reviewed targets a different set of hedonist commitments, and each raises an independent challenge for those commitments (or multiple challenges, in the case of the true judges model). This seems to suggest that the objections are best assessed separately, by considering them one at a time. But an entirely piecemeal approach runs the risk missing ways in which the the objections reinforce each other at various junctures. We see such mutual reinforcement, for example, when the preference hedonist responds to the normativity objection by locating aesthetic experiences' good-making feature in their relation to the true judges' experiential preferences, as opposed to their phenomenology (see the end of Section 3.1). While this move might appear to defuse the normativity objection, in effect it simply kicks the can down the road, to questions about whether the true judges model can carry the explanatory burden (Section 3.6). And we see it again, when hedonists try to head off the fungibility objection by making aesthetic goods essential constituents of the experiences that ground their value (end of Section 3.3). By making this move, they incur the burden of giving a non-circular account of the good-making or reason-giving features of experiences so constituted (a burden reminiscent of the one raised by the normativity objection).

Thus, although the objections are logically independent, the threat they pose is more than merely cumulative. This should not come entirely as a surprise. Aesthetic hedonism is perhaps best thought of not as a single, self-contained theory, but as a theoretical framework, research programme, or paradigm. As such, it calls for evaluation on more holistic grounds than whether it can answer or accommodate individual objections considered in isolation.

Thinking of hedonism in this way, as theoretical framework or research programme, foregrounds a significant difference among the objections. On the one hand, some of them - what we might 
call undermining objections - agitate from a perspective compatible with the hedonist programme's basic presuppositions. Such objections take hedonism's target explananda and starting assumptions as given, and function by showing how hedonist theories run into trouble by their own lights. Revolutionary objections, on the other hand, attack hedonism from an external perspective, contesting its starting assumptions and advocating for a shift in the common ground for theorizing about aesthetic value. Although the distinction is admittedly a blurry one, the first five lines of argument reviewed (Sections 3.1-3.5) can roughly be categorized as undermining objections. They work within the constraints the hedonist programme sets for itself, and their effective force is to compel dyed-in-the-wool hedonists to supplement, adjust, clarify, or give up some part of their theories. In principle, hedonists can continue to answer or deflect undermining arguments indefinitely, with countermoves or partial concessions designed especially for each objection. But such targeted replies usually come at a cost to a theory's simplicity, parsimony, and explanatory power, and, as we saw, they may complicate the hedonist's responses to other objections or introduce new vulnerabilities into the theory.

By contrast, the objections against the true judges (Section 3.6) provide the clearest example of revolutionary impetus. Instead of just trying to prove hedonism wrong by its own lights, these criticisms strike at the core of the hedonist programme by challenging its methodological assumptions and its pre-theoretical construal of the target explananda. At the level of methodology, they suggest that aesthetic value theory should privilege non-ideal theorizing, aiming in the first instance to offer guidance to flesh-and-blood aesthetic agents navigating the messiness of aesthetic reality (see especially Kieran 2008: 280-83 but also Lopes 2018: 78-81; for a discussion of the ideal/non-ideal theory distinction, see Mills 2005). In addition, these criticisms contest the hedonist programme's traditional approach of taking the nature and aptness conditions of aesthetic judgement as starting point for theorizing about aesthetic value (see Lopes 2018: 32-36). At the level of the hedonist programme's construal of the target explananda, the criticisms of the true judges model contend that individual variance and idiosyncrasies in our aesthetic tastes an commitments (Riggle 2015), as well as specialization by aesthetic domain and activity (Lopes 2018), are central facts of aesthetic life that should be positively explained rather than merely accommodated by a theory of aesthetic value. 
Thus, by attacking not just the contents of hedonist theories, but also the hedonist's methods and starting assumptions, the arguments against true judges raise a more fundamental challenge for aesthetic hedonism than the other five lines of argument reviewed. That is not to say that those arguments pose lesser problems, especially when taken together. But to respond to the arguments against true judges, hedonists must either defend their whole theoretical approach against alternatives, or show that proposed alternative approaches to aesthetic value theory still support a broadly hedonic answer to the normative question. Neither of these responses can be executed by merely supplementing or making minor changes to existing versions of hedonism, and, ultimately, both require reconsidering the hedonist programme as a whole in light of other options.

\section{ALTERNATIVES TO AESTHETIC HEDONISM}

Philosophical paradigm shifts seldom happen overnight, and although the objections reviewed pose considerable challenges, it would be overhasty to rule out future versions of hedonism capable of evading them all. In fact, there is room for good work within the hedonist paradigm with an eye to overcoming the objections. Such work is important especially where it amounts to more than ad hoc patches and tweaks to existing hedonist theories. In this regard, Matthen's (2017) recent functionalist account of aesthetic pleasure, along with the theory of aesthetic value he builds on it (Matthen 2018), provides striking illustration of how one might blaze a fresh trail for the hedonist cause.

But there is also reason to worry that hedonism's continued dominance in aesthetics unduly constrains our thinking about ancillary issues. The hedonist answer to the normative question has long been so prominent that alternatives have become difficult to envision. This has had the unfortunate upshot that the bulk of research on phenomena as various as aesthetic perception, judgement, appreciation, disagreement, testimony, personality, and motivation, to name but a few, often simply proceeds against the backdrop of hedonist assumptions. As Shelley (2019) puts it, hedonism is embedded in the 'default settings' for work on aesthetic value, and if the last section's objections show anything, it is that this default status has not been earned. Thus, until 
answered, the objections serve to license and motivate work on non-hedonic theories of aesthetic value.

Luckily, the search for alternatives is already gaining steam and the avenues to explore are many. It should come as no surprise that hedonism's biggest critics are at the forefront of this search. Enmeshed in his case against aesthetic hedonism, Lopes's (2018) own network theory couches aesthetic normativity as a type of performance normativity, with the value of achievement displacing pleasure in the fundamental explanatory role. Central to Lopes's network theory is the idea that aesthetic values are deeply embedded in social practices that serve as the 'scaffolding' for valuable aesthetic achievements. In as yet unpublished work, Shelley (ms.) develops the robustly realist account of aesthetic value that his published criticisms of hedonism have sometimes hinted at (see for example Shelley 2010: 715-20). His account-which we might call the Auburn view of aesthetic value (see also Gorodeisky 2019: §6, Watkins \& Shelley 2012: 349-50) - makes aesthetic value into a normative primitive that cannot be analysed in terms of further normative concepts. The thought is that aesthetic value's normative status is on a par with the basic normative status of truth in the epistemic domain.

Other recent proposals for non-hedonic theories have been floated in skeletal form and await fleshing out. Peter Goldie (2007, 2008) and Matthew Kieran (2009) both advocate for an approach on which aesthetic normativity is cashed out on the model of a virtue-based conception of aesthetic character. Thi Nguyen (2019) gestures towards a practice-centred view in which the norms of aesthetic practices are contingently constructed around the value of active and effortful engagement with aesthetic goods, while the final value of such engagement accrues in turn from its expression of individual autonomy. Riggle (2015: 444-47) sketches the outlines of an account in which the hedonic ideal of the Humean true judges is supplanted by the ideal of having style. The normativity of this ideal, as Riggle understands it, is grounded in style's role in building and maintaining 'communities of individuals' (see Riggle 2017).

Leaning on Parfit's (1984) taxonomy of three major types of theories of value in the prudential domain, Robbie Kubala (2019: 261) has suggested in passing that, instead of hedonism or an objective list theory, a desire-satisfaction theory of normativity might be especially well suited to 
aesthetic value. Having made the suggestion, however, Kubala goes on to ask whether we really need to choose: could we not perhaps accept a pluralist account on which the normativity of aesthetic value is sourced, on different occasions, in different kinds of basic goods, whether those goods are experiential or objective or constitutively tied to our desires? In recent work, Antonia Peacocke (ms.) has also endorsed a kind of pluralism about the normativity of aesthetic value (or 'liberalism', in her terminology). Peacocke grants a version of the hedonist answer to the demarcation question, claiming that aesthetic value must be tied to the value of perceptual experiences in some important sense. But, unlike the hedonist, she denies that it must in all cases be grounded in the intrinsic or final value of those experiences. Instead, Peacocke allows cases in which aesthetic values are grounded in the instrumental value of certain experiences, such that they derive their normativity from non-hedonic final goods (such as, for example, special kinds of insight or understanding) to which the experiences are essential or ineliminable means. In other words, while Peacocke's account shares much with hedonism, it permits the normativity of aesthetic values to be sourced in goods beyond the aesthetic experiences that give us access to those values.

The call to look beyond aesthetic hedonism also provides impetus to re-examine historical figures and attend to theorists outside the mainstream of the Euro tradition whose work on aesthetic value does not fit cleanly within the hedonist paradigm. Samantha Matherne and Nick Riggle (ms.), for example, revisit Schiller's aesthetics to extract a broadly 'communitarian' view that resonates with Riggle's own and casts aesthetic value as primarily a social good. Lopes (2019) provides an example from South Asian aesthetics, by reading K.C. Bhattacharyya's (2011) rasa theory as a kind of hybrid view that answers the demarcation question in terms of aesthetic pleasure, but departs from hedonism by answering the normative question by appeal to the value of the freedom characteristic of such pleasure. Julianne Chung $(2018,2019)$ considers the picture of aesthetic value that emerges from a family of views in East Asian philosophy views that emphasize the deep interconnectedness of individuals with others and with their natural surroundings. On this picture, the normativity of (some) aesthetic values is grounded in their capacity to engender awareness of how we are connected with aesthetic objects and, by extension, with things in general. 
Once the outlines of some alternative answers to the normative question come into view, hedonism's hegemony in aesthetics starts to look less inevitable, perhaps even surprising. Why is it that, in philosophical work on other normative domains, hedonic or experiential theories represent just one among several major theoretical strands, but in contemporary aesthetics, they have largely monopolized the field? Where are the aesthetic perfectionists, the desire-satisfaction and objective list theorists about aesthetic value? For a long time their absence from the field seemed to indicate the implausibility of any theory other than hedonism. It is fast becoming clear that this appearance was misleading: viable non-hedonic theories were not impossible, they had just not been articulated yet. With hedonism's dominance a little less secure, we might well be entering an unusually auspicious time for new work on aesthetic value. ${ }^{6}$

\section{References}

Aydede, M. 2014. How to Unify Theories of Sensory Pleasure: An Adverbialist Proposal, Review of Philosophy and Psychology 5: 119-133. https://doi.org/10.1007/s13164-014-0175-6

Berleant, A. 2016. Re-thinking Aesthetics. New York: Routledge. https://doi.org/ $\underline{10.4324 / 9781315244327}$

Bhattacharyya, K. C. 2011. The Concept of Rasa, in Indian Philosophy in English: From Renaissance to Independence, eds. N. Bhushan and J. L. Garfield. Oxford: Oxford University Press, 195-206. http://doi.org/10.1093/acprof:osobl/9780199769261.001.0001 Budd, M. 1985. Music and the Emotions: The Philosophical Theories. London: Routledge. Budd, M. 1995. Values of Art: Painting, Poetry, and Music. London: Penguin.

\footnotetext{
${ }^{6}$ My thanks to David Friedell, Thi Nguyen, and Nick Riggle for comments on earlier drafts. For helpful discussion, thanks to Aleksey Balotskiy, Dom Lopes, and the members of the 2018 Summer Seminar on Beauty and Why It Matters in Vancouver.
} 
Budd, M. 2008. Aesthetic Essence, in his Aesthetic Essays. Oxford: Oxford University Press, 3147. http://doi.org/10.1093/acprof:oso/9780199556175.001.0001

Bullough, E. 1912. 'Psychical Distance' as a Factor in Art and an Aesthetic Principle, British Journal of Psychology 5: 87-117.

Carlson, A., and Parsons, G. 2008. Functional Beauty. Oxford: Clarendon Press. http://doi.org/ 10.1093/acprof:oso/9780199205240.001.0001

Carroll, N. 2002. Aesthetic Experience Revisited, British Journal of Aesthetics 42/2: 145-68. https://doi.org/10.1093/bjaesthetics/42.2.145

Carroll, N. 2012. Recent Approaches to Aesthetic Experience, Journal of Aesthetics and Art Criticism 70/2:165-177. https://doi.org/10.1111/j.1540-6245.2012.01509.x

Chung, J. 2018. Moral Cultivation: Japanese Gardens, Personal Ideals, and Ecological Citizenship, Journal of Aesthetics and Art Criticism 76/4: 507-18. https://doi.org/10.1111/ jaac. 12597

Chung, J. 2019. The Oneness Hypothesis and Aesthetic Obligation, Philosophy and Phenomenological Research 99/2: 501-7. https://doi.org/10.1111/phpr.12630

Crisp, R. 2006. Hedonism Reconsidered, Philosophy and Phenomenological Research 73/3: 619-45. http://doi.org/10.2307/40041013

Crisp, R. 2007. Sidgwick's Hedonism, in Proceedings of the World Congress on Henry Sidgwick: Happiness and Religion, eds. P. Buccolo, R. Crisp, and B. Schultz. Catania: University of Catania, 104-57.

Cross, A. 2017. Obligations to Artworks as Duties of Love, Estetika 54/1: 85-101.

Davies, D. 2004. Art as Performance. Oxford: Blackwell. http://doi.org/10.1002/9780470774922

Davies, S. 1994. The Evaluation of Music, in What is Music?, ed. P. Alperson, University Park, PA: Pennsylvania State University Press, 307-25.

Dickie, G. 1988. Evaluating Art. Philadelphia: Temple University Press.

Dodd, J. 2014. On a Proposed Test for Artistic Value. British Journal of Aesthetics 54/4: 395407. http://doi.org/https://doi.org/10.1093/aesthj/ayu028

Elster, J. 1983. Sour Grapes: Studies in the Subversion of Rationality. Cambridge: Cambridge University Press. https://doi.org/10.1017/CBO9781139171694

Forsey, J. 2017. Aesthetic Experience, Aesthetic Value, Estetika 54/2: 175-88. 
Goldie, P. 2007. Towards a Virtue Theory of Art, British Journal of Aesthetics 47/4: 372-87. https://doi.org/10.1093/aesthj/aym022

Goldie, P. 2008. Virtues of Art and Human Well-Being, Aristotelian Society Supplementary Volume 82/1: 179-95. https://doi.org/10.1111/j.1467-8349.2008.00168.x

Goldman, A. 1995. Aesthetic Value. Boulder: Westview Press.

Goldman, A. 2006. The Experiential Account of Aesthetic Value, Journal of Aesthetics and Art Criticism 64/3: 333-42. https://doi.org/10.1111/j.1540-594X.2006.00211.x

Gorodeisky, K. 2019. On Liking Aesthetic Value, Philosophy and Phenomenological Research. Advance online publication. https://doi.org/10.1111/phpr.12641

Hanson, L. 2013. The Reality of (Non-aesthetic) Artistic Value, Philosophical Quarterly 63/252: 492-508. https://doi.org/10.1111/1467-9213.12026

Huddleston, A. 2012. In Defense of Artistic Value, Philosophical Quarterly 62/249: 705-14. https://doi.org/10.1111/j.1467-9213.2012.00089.x

Hume, David. 1777. Of the Standard of Taste. Four Dissertations. London: Millar, 227-49.

Iseminger, G. 2004. The Aesthetic Function of Art. Ithaca, NY: Cornell University Press.

Iseminger, G. 2005. The Aesthetic State of Mind, in Contemporary Debates in Aesthetics and the Philosophy of Art, ed. Matthew Kieran. Oxford: Blackwell, 98-112.

Kieran, M. 2008. Why Ideal Critics Are Not Ideal: Aesthetic Character, Motivation, and Value, British Journal of Aesthetics 48/3: 278-94. https://doi.org/10.1093/aesthj/ayn021

Kieran, Matthew. 2009. The Vice of Snobbery: Aesthetic Knowledge, Justification, and Virtue in Art Appreciation, Philosophical Quarterly 60/239: 243-63. https://doi.org/10.1111/ j.1467-9213.2009.615.x

King, A. 2019. [Review of Being for Beauty: Aesthetic Agency and Value, by D. M. Lopes], British Journal of Aesthetics. Advance online publication. https://doi.org/10.1093/aesthj/ ayz014

King, A. ms. Normativity and the Case of Aesthetics. Article manuscript in preparation.

Kölbel, M. 2016. Aesthetic Judge-Dependence and Expertise, Inquiry 59/6: 589-617. https:// doi.org/10.1080/0020174X.2016.1208917

Kubala, R. 2018. Grounding Aesthetic Obligations, British Journal of Aesthetics 58/3: 271-85. https://doi.org/10.1093/aesthj/ayy015 
Kubala, R. 2019. [Review of Being for Beauty: Aesthetic Agency and Value, by D. M. Lopes], Estetika 56/2: 250-62.

Levinson, J. 1992. Pleasure and the Value of Works of Art, British Journal of Aesthetics 32/4: 295-306. https://doi.org/10.1093/bjaesthetics/32.4.295

Levinson, J. 2002. Hume's Standard of Taste: The Real Problem, Journal of Aesthetics and Art Criticism 60/3: 227-38. https://doi.org/10.1111/1540-6245.00070

Levinson, J. 2010. Artistic Worth and Personal Taste, Journal of Aesthetics and Art Criticism 68/3: 225-33. https://doi.org/10.1111/j.1540-6245.2010.01414.X

Levinson, J. 2013. Reply to Riggle: Aesthetic History, Personality, and Profile, Journal of Aesthetics and Art Criticism 71/3: 281-82. https://doi.org/10.1111/jaac.12023

Levinson, J. 2016. Toward an Adequate Conception of Aesthetic Experience, in Aesthetic Pursuits: Essays in Philosophy of Art. Oxford: Oxford University Press, 28-46. http:// doi.org/10.1093/acprof:oso/9780198767213.001.0001

Lopes, D. M. 2011. The Myth of (Non-Aesthetic) Artistic Value, Philosophical Quarterly 61/244: 518-36. https://doi.org/10.1111/j.1467-9213.2011.700.x

Lopes, D. M. 2015. Aesthetic Experts: Guides to Value, Journal of Aesthetics and Art Criticism 73/3: 235-246. https://doi.org/10.1111/jaac.12170

Lopes, D. M. 2018. Being for Beauty: Aesthetic Agency and Value. Oxford: Oxford University Press. http:/doi.org/10.1093/oso/9780198827214.001.0001

Lopes, D. M. 2019. Feeling for Freedom: K. C. Bhattacharyya on Rasa, British Journal of Aesthetics. Advance online publication. https://doi.org/10.1093/aesthj/ayz022

Matthen, M. 2017. The Pleasure of Art, Australasian Philosophical Review 1/1: 6-28. https:// doi.org/10.1080/24740500.2017.1287034

Matthen, M. 2018. New Prospects for Aesthetic Hedonism, in Social Aesthetics and Moral Judgment: Pleasure, Reflection and Accountability, ed. J. A. McMahon. New York: Routledge, 13-33.

Matherne, S. ms. Edith Landmann-Kalischer on Aesthetic Demarcation and Normativity. Article manuscript in preparation.

Matherne, S., and Riggle, N. ms. Schiller on Freedom and Aesthetic Value, Parts 1 and 2. Article manuscripts in preparation. 
Melchionne, K. 2010. On the Old Saw 'I know nothing about art but I know what I like', Journal of Aesthetics and Art Criticism 68/2: 131-41. https://doi.org/10.1111/ j.1540-6245.2010.01398.x

Mills, C. W. 2005. 'Ideal Theory' as Ideology, Hypatia 20/3: 165-84. https://doi.org/10.1111/ j.1527-2001.2005.tb00493.x

Mothersill, M. 1989. Hume and the Paradox of Taste, in Aesthetics: A Critical Anthology, ed. G. Dickie, R. Sclafani, and R. Roblin. New York: St Martin's, 269-86.

Nguyen, C. T. 2019. Autonomy and Aesthetic Engagement, Mind. Advance online publication. https://doi.org/10.1093/mind/fzz054

Nozick, R. 1974. Anarchy, State, and Utopia. Oxford: Blackwell.

Nehamas, A. 2007. Only a Promise of Happiness: The Place of Beauty in a World of Art. Princeton: Princeton University Press.

Parfit, D. 1984. Reasons and Persons. Oxford: Clarendon Press. http://doi.org/ 10.1093/019824908X.001.0001

Peacocke, A. ms. Let's Be Liberal. Article manuscript in preparation.

Riggle, N. 2013. Levinson on the Aesthetic Ideal, Journal of Aesthetics and Art Criticism 71/3: 277-81. https://doi.org/10.1111/jaac.12022

Riggle, N. 2015. On the Aesthetic Ideal, British Journal of Aesthetics 55/4: 433-47. https:// doi.org/10.1093/aesthj/ayv026

Riggle, N. 2016. On the Interest in Beauty and Disinterest, Philosopher's Imprint 16/9: 1-14. http://hdl.handle.net/2027/spo.3521354.0016.009

Riggle, N. 2017. On Being Awesome: A Unified Theory of How Not to Suck. London: Penguin.

Sharpe, R. A. 2000. The Empiricist Theory of Artistic Value, Journal of Aesthetics and Art Criticism 58/4: 321-32. http://doi.org/10.2307/432178

Shelley, J. 2010. Against Value Empiricism in Aesthetics, Australasian Journal of Philosophy 88/4: 707-20. https://doi.org/10.1080/00048400903207104

Shelley, J. 2011. Hume and the Value of the Beautiful, British Journal of Aesthetics 51/2: 21322. https://doi.org/10.1093/aesthj/ayr007

Shelley, J. 2013. Hume and the Joint Verdict of True Judges, Journal of Aesthetics and Art Criticism 71/2: 146-53. https://doi.org/10.1111/jaac.12003 
Shelley, J. 2017. The Concept of the Aesthetic, in Stanford Encyclopedia of Philosophy, ed. E. N. Zalta, Winter 2017 edn. (First version published in Fall 2009 edn.). https:// plato.stanford.edu/archives/win2017/entries/aesthetic-concept

Shelley, J. 2019. The Default Theory of Aesthetic Value, British Journal of Aesthetics 59/1: 1-12. https://doi.org/10.1093/aesthj/ayy044

Shelley, J. ms. The Aesthetic Value Question. Book manuscript in preparation.

Sibley, F. 2001. Aesthetic and Non-aesthetic, in Approach to Aesthetics: Collected Papers on Philosophical Aesthetics, eds. J. Benson, H. B Redfern, and J. R. Cox. Oxford: Clarendon Press, 33-51. Sibley, F. 2001. http://doi.org/10.1093/0198238991.001.0001

Sidgwick, H. 1907. The Methods of Ethics, 7th edn. London: MacMillan.

Stang, N. F. 2012. Artworks Are Not Valuable for Their Own Sakes, Journal of Aesthetics and Art Criticism 70/3: 271-80. https://doi.org/10.1111/j.1540-6245.2012.01519.x

Stecker, R. 1997. Artworks: Definition, Meaning, Value. University Park: Penn State University Press.

Stecker, R. 2006. Aesthetic Experience and Aesthetic Value, Philosophy Compass 1/1: 1-10. https://doi.org/10.1111/j.1747-9991.2006.00007.x

Stecker, R. 2012. Artistic Value Defended, Journal of Aesthetics and Art Criticism 70/4: 355-62. https://doi.org/10.1111/j.1540-6245.2012.01527.x

Strohl, M. 2019. Art and Painful Emotion, Philosophy Compass 14/1: e12558. http://doi.org/ $\underline{10.1111 / \mathrm{phc} 3.12558}$

Sumner, L. W. 1996. Welfare, Happiness, and Ethics. Oxford: Clarendon Press. http://doi.org/ 10.1093/acprof:oso/9780198238782.001.0001

Walton, K. L. 1993. How Marvelous! Towards a Theory of Aesthetic Value, Journal of Aesthetics and Art Criticism 51/3: 499-510. http://doi.org/10.2307/431521

Watkins, M., and Shelley, J. 2012. Response-Dependence about Aesthetic Value, Pacific Philosophical Quarterly 93/3: 338-52. https://doi.org/10.1111/j.1468-0114.2012.01429.x

Wolf, S. 2015. Good-for-Nothings, in The Variety of Values: Essays on Morality, Meaning, and Love. Oxford: Oxford University Press, 67-86. http://doi.org/10.1093/acprof:oso/ $\underline{9780195332803.001 .0001}$

Wolterstorff, N. 2015. Art Rethought: the Social Practices of Art. Oxford: Oxford University Press. http://doi.org/10.1093/acprof:oso/9780198747758.001.0001 